\title{
Effect of obesity on rat reproduction and on the development of their adult offspring
}

\author{
K.E. Campos, G.T. Volpato, I.M.P. Calderon, M.V.C. Rudge and D.C. Damasceno \\ Departamento de Ginecologia e Obstetrícia, Faculdade de Medicina de Botucatu, Universidade Estadual \\ Paulista (UNESP), Botucatu, SP, Brasil
}

Correspondence to: D.C. Damasceno, Departamento de Ginecologia e Obstetrícia, Faculdade de Medicina de Botucatu, UNESP, Distrito de Rubião Júnior, s/n, 18618-000 Botucatu, SP, Brasil

E-mail: kecampos@yahoo.com.br

\begin{abstract}
The aim of the present study was to assess the reproductive parameters of obese Wistar rats and to determine the frequency of their obese adult offspring. Neonatal rats were divided into two groups: $F_{1}$ generation, induced to obesity by monosodium glutamate (MSG; $F_{1} M S G, N=30$ ), and rats given saline $\left(F_{1} C O N, N=13\right)$. At 90 days of age all animals were mated, producing the $F_{2}$ offspring $\left(F_{2} C O N, N=28 ; F_{2} M S G, N=15\right)$. Reproductive parameters (fertility, pregnancy, and delivery indexes) were evaluated in $F_{1}$ rats. $F_{2}$ newborns were weighed, and the obesity parameter for $F_{1}$ and $F_{2}$ generations was determined from months 5 to 7 of life. At month 7, periovarian fat was weighed and no differences were found. Mean newborn weight also did not differ. The $F_{1}$ and $F_{2}$ MSG groups presented approximately $90 \%$ of obese rats since month 5 of life, whereas $F_{1}$ and $F_{2} C O N$ groups presented only $33 \%$. There was no difference in periovarian weight among groups. Although obesity did not affect reproductive parameters, obese dams $\left(\mathrm{F}_{1} \mathrm{MSG}\right)$ were responsible for the appearance of obesity in the subsequent generation. Thus, obesity induced by neonatal MSG administration did not interfere with reproduction, but did provide a viable model for obesity in second-generation adult Wistar rats. This model might contribute to a better understanding of the pathophysiological mechanisms involved in transgenerational obesity.
\end{abstract}

Key words: Obesity; Offspring; Fertility; Wistar rats; Monosodium glutamate; Transgeneration

Research supported by CAPES.

Publication supported by FAPESP.

Received December 15, 2006. Accepted November 30, 2007

Although the negative effects of obesity on reproductive function were first documented more than 2000 years ago by Hippocrates, few scientific investigations of women have dealt with the etiology of this unfavorable condition (1). Obesity is rapidly growing among women in general and women of fertile age (2). Clinical investigations show that obese women have a greater prevalence of amenorrhea and infertility. It is common to find greater risks of complications during pregnancy among these women such as hypertension, gestational diabetes and greater susceptibility to complications during delivery, which result in unplanned cesarean surgeries. Maternal obesity can have a negative effect on children's health (3).

Since it is difficult to determine obesity-induced reproductive complications in women, experimental studies are carried out to induce obesity. The model of neonatally monosodium glutamate (MSG)-treated rats is of special interest regarding the development of obesity (4-6). Neonatal treatment with MSG has been shown to destroy hypothalamic arcuate nucleus neurons, resulting in several endocrine disturbances (7), stunted growth, and obesity (8).

In the context of the existing relationship between obesity and complications of female reproduction and considering the interest in hereditary consequences (transgenerational effect), the objective of the present study aims to evaluate the reproductive parameters of Wistar rats treated with MSG during the neonatal period and to determine the frequency of their obese offspring.

Wistar rats were kept in collective cages under con- 
trolled conditions of temperature $\left(22 \pm 3^{\circ} \mathrm{C}\right)$, light (12-h light/dark cycle) and relative humidity (60 $\pm 5 \%)$. The animals were fed laboratory chow (Purina ${ }^{\circledR}$ ) and had free access to tap water. The animals were cared for in accordance with the principles of the Guide for Care and Use of Experimental Animals. The local Ethics Committee of Animal Experimentation approved all the experimental procedures of the present study.

Female newborns were divided into two groups: rats receiving subcutaneously $(s c)$ saline solution $(2.0 \% \mathrm{NaCl}$, control) at days $2,4,6,8$, and 10 of life ( $F_{1} C O N$ group, $N=$ $13)$, and rats receiving a solution of $\mathrm{MSG}(4.0 \mathrm{mg} / \mathrm{g}$ body weight, $s c)$ on the same days ( $F_{1} M S G$ group, $N=30$ ) $(4,5,9)$. After weaning, rats were housed 4 to a cage and kept under controlled conditions.

Obesity was determined by the Lee index at months 3 , 5,6 , and 7 of life for each rat, calculated by the cube root of body weight $(\mathrm{g}) \times 10$ / naso-anal length $(\mathrm{mm})$, for which a value equal to or lower than 0.300 was classified as normal at month 3 of life. For values higher than 0.300 , the rats were classified as obese (9). In the 3rd month, rats classified as obese were included in the experiment and mated. Each female $\left(\mathrm{F}_{1} \mathrm{CON}\right.$ group, $\mathrm{N}=8$; $\mathrm{F}_{1} \mathrm{MSG}$ group, $\mathrm{N}=5$, total $=13$ female rats) was mated with 1 normal male rat (total males used $=13$ ). Several indexes were evaluated to estimate female reproductive performance: fertility index was calculated by the number of pregnant females $x 100$ / number of mated females; delivery index was calculated by the number of delivering females $x 100 /$ number of pregnant females, and pregnancy index was determined by the number of dams with live newborns x 100 / number of pregnant females (10). At month 7 all rats were anesthetized and killed and total periovarian fat was weighed $(4,11)$.

The female offspring of $F_{1}$ generation was kept with their dams until day 21 of life. After weaning all $F_{2}$ pups were separated from their dams and denominated according to maternal experimental group: $\mathrm{F}_{2} \mathrm{CON}(\mathrm{N}=28$, obtained from $\mathrm{F}_{1} \mathrm{CON}$ dams) and $\mathrm{F}_{2} \mathrm{MSG}(\mathrm{N}=15$, obtained from $F_{1} M S G$ rats; Figure 1). Food and tap water were given ad libitum. $F_{2}$ rats were kept until month 7 of life. The Lee index was evaluated monthly from the 5th to 7th month of life (9). In month 7, $F_{2}$ rats were anesthetized and killed to collect and weigh periovarian fat. Data regarding the reproductive parameters were analyzed statistically by the ztest, with $z>1.96$ being considered significant (12). Periovarian fat weight data were analyzed by analysis of variance (ANOVA) followed by the multiple comparisons Tukey test (13). The frequency of obese animals was calculated by the $\chi^{2}$ test. The level of statistical significance was set at $5 \%(P<0.05)(12)$.
The negative effects of obesity on reproductive physiology have been studied for many years. In the present study, all $13 \mathrm{~F}_{1} \mathrm{CON}$ rats that started the experiment reached adult age and were submitted to mating and $84.6 \%$ of them presented a positive diagnosis of pregnancy. Twenty-one of the $30 \mathrm{~F}_{1} \mathrm{MSG}$ rats $(70 \%)$ reached adult age and $9(30 \%)$ died before this period. We suggest that death in the MSG group occurred due to the fact that blood brain barrier was not fully formed during the first 10 days of life and, therefore, permitted MSG passage, leading to its pharmacological action in the central nervous system $(6,7)$. This fact caused an exhaustion of energy stores and cell death, which impaired other vital functions, affecting neonatal development.

Obesity may interfere with many ovarian and extraovarian functions, thereby reducing both ovulatory and fertility rates in otherwise healthy women (14). In the present study, pregnancy was confirmed in 14 of 21 obese rats mated $(66.7 \%)$, but no difference was found compared to $\mathrm{F}_{1} \mathrm{CON}(\mathrm{z}<1.96)$. Only 5 of 14 pregnant obese rats $(35.7 \%)$ delivered when compared to $\mathrm{F}_{1} \mathrm{CON}(72.7 \%)$, but the difference was non-significant $(z<1.96$; Table 1). These results did not agree with literature data because obesity affects female fertility, with a greater risk of ovulatory infertility, that is increased in women with a high body mass index $(3,9)$.

In the present study, the mean weight of the $\mathrm{F}_{2} \mathrm{MSG}$ group did not differ significantly from that of $F_{2} C O N(P>$ 0.05 ; Table 1). All $F_{1} M S G$ rats were classified as obese $(100 \%)$ according to the Lee index. The periovarian fat of obese $F_{1}$ and $F_{2}$ rats did not differ significantly from control $(P>0.05$; Table 1). There was an increased percentage of obese rats in the $\mathrm{F}_{2} \mathrm{MSG}$ group compared to the $\mathrm{F}_{2} \mathrm{CON}$ group $(P<0.05)$. This result confirms that maternal obesity caused obesity in the subsequent generation and demonstrates that the experimental model employed was viable for obtaining a similar clinical diagnosis of obese patients based on body mass index. Children of obese parents have an increased risk of becoming obese compared to children of parents of normal weight (15). The Lee index values of $F_{1}$ and $F_{2}$ MSG were higher, a fact probably justified by lower body length because obesity disorders contribute to a reduction of body protein by the presence of high levels of circulating corticosterone (16). There is considerable experimental and clinical evidence that an altered body composition before and during pregnancy produces altered metabolism in the offspring; unbalanced maternal nutrition or overweight and gestational diabetes are all associated with changes in metabolic control in the offspring, which then have a greater propensity to develop diabetes and/or obesity (17). However, there is little infor- 
Table 1. Reproductive performance, newborn mean weight, obesity month frequency (\%), and periovarian fat weight of controls (CON, saline-treated rats) and obese females (MSG, monosodium glutamate-treated rats) in both generations $\left(F_{1}\right.$ and $\left.F_{2}\right)$.

\begin{tabular}{|c|c|c|c|c|}
\hline & \multicolumn{2}{|c|}{$F_{1}$ generation } & \multicolumn{2}{|c|}{$F_{2}$ generation } \\
\hline & $\mathrm{F}_{1} \mathrm{CON}(\mathrm{N}=13)$ & $\mathrm{F}_{1} \mathrm{MSG}(\mathrm{N}=30)$ & $\mathrm{F}_{2} \mathrm{CON}(\mathrm{N}=28)$ & $\mathrm{F}_{2} \mathrm{MSG}(\mathrm{N}=15)$ \\
\hline Mated rats & $13 / 13(100 \%)$ & $21 / 30(70 \%)$ & - & - \\
\hline Fertility index & $11 / 13(84.6 \%)$ & $14 / 21(66.7 \%)$ & - & - \\
\hline Pregnancy index & $8 / 11(72.7 \%)$ & $5 / 14(35.7 \%)$ & - & - \\
\hline Delivery index & $8 / 11(72.7 \%)$ & $5 / 14(35.7)$ & - & - \\
\hline Mean weight of newborn (g) & $3.50 \pm 0.6$ & $4.31 \pm 1.3$ & $3.72 \pm 1.2$ & $4.64 \pm 1.0$ \\
\hline Obesity month 5 & $12.5 \%$ & $100 \% *$ & $28.6 \%$ & $93.3 \%{ }^{*}$ \\
\hline Obesity month 6 & $12.5 \%$ & $100 \% *$ & $48.4 \%$ & $80 \% *$ \\
\hline Obesity month 7 & $50 \%$ ** & $100 \%$ & $48.4 \%$ & $100 \% *$ \\
\hline Periovarian fat weight (g) & $3.07 \pm 0.5$ & $3.57 \pm 0.3$ & $2.57 \pm 0.9$ & $3.35 \pm 2.31$ \\
\hline
\end{tabular}

Data are reported as means $\pm S D$, number or percent.

${ }^{*}$ Significant difference compared to control group $\left(\mathrm{P}<0.05-\chi^{2}\right.$ test). ${ }^{* *}$ Significant difference compared to 5 th and 6 th months $\left(\mathrm{P}<0.05, \chi^{2}\right.$ test).

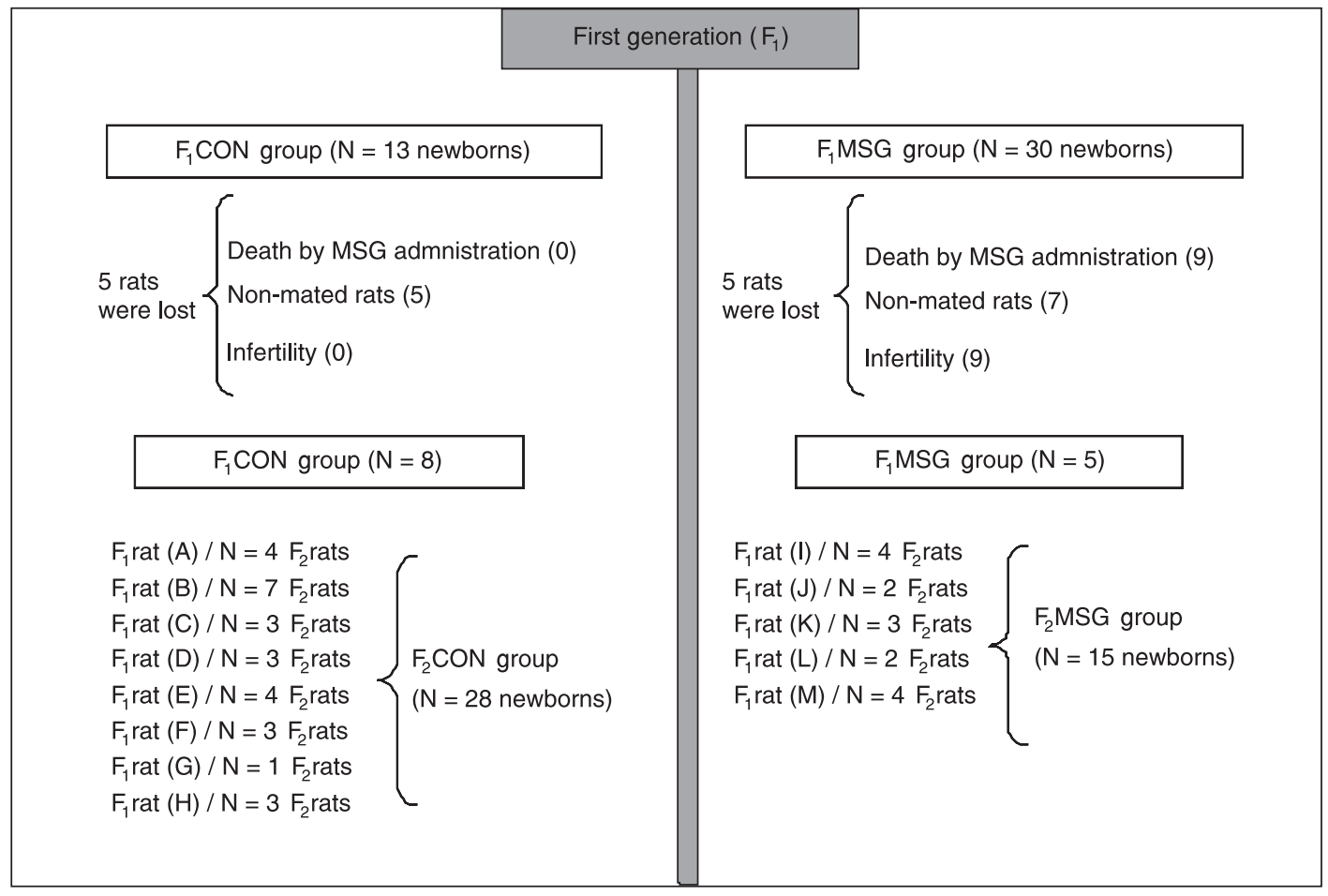

Figure 1. Rat generation scheme $\left(F_{1}\right.$ and $\left.F_{2}\right)$ of obese rats neonatally treated with monosodium glutamate $\left(F_{1} M S G\right.$ group $)$ and of the control group $\left(\mathrm{F}_{1} \mathrm{CON}\right)$ and their respective offspring $\left(\mathrm{F}_{2}\right.$ generation). $F_{2}$ rat distribution was almost similar in both groups (approximately $\mathrm{N}=3 \mathrm{~F}_{2}$ female rat/dam). 
mation about the pathological mechanisms of transgenerational obesity.

In the 7th month of life, there was a significant increase in number of obese animals $(50 \%)$ in the $F_{1}$ CON group compared to other months $(P<0.05)$. The presence of obesity in $\mathrm{F}_{1}$ and $\mathrm{F}_{2} \mathrm{CON}$ rats at month 7 of life might be justified by the aging process. In rats, this process starts at the end of month 6 of life (18). Similarly, in month 7 of life, $F_{1}$ and $F_{2}$ MSG rats presented a higher rate of obesity compared to their respective control groups. There is evidence that obesity is present in the human population and its prevalence increases as the population ages (19).

The most interesting result of the present study is that, although obesity did not influence the reproductive param-

\section{References}

1. Bray GA. Obesity: historical development of scientific and cultural ideas. Int J Obes 1990; 14: 909-926.

2. World Health Organization. Obesity: preventing and managing the global epidemic. Report of a WHO Consultation on Obesity, 3-5 June. Geneva: World Health Organization; 1997.

3. Linne Y. Effects of obesity on women's reproduction and complications during pregnancy. Obes Rev 2004; 5: 137143.

4. Mozes S, Sefcikova Z, Lenhardt L, Racek L. Obesity and changes of alkaline phosphatase activity in the small intestine of 40 - and 80 -day-old rats subjected to early postnatal overfeeding or monosodium glutamate. Physiol Res 2004; 53: $177-186$.

5. Ribeiro EB, Marmo MR, Andrade IS, Dolnikoff MS. Effect of fasting on monosodium glutamate-obese rats. Braz J Med Biol Res 1989; 22: 917-921.

6. Bueno AA, Oyama LM, Estadella D, Habitante CA, Bernardes BS, Ribeiro EB, et al. Lipid metabolism of monosodium glutamate obese rats after partial removal of adipose tissue. Physiol Res 2005; 54: 57-65.

7. Olney JW. Brain lesions, obesity, and other disturbances in mice treated with monosodium glutamate. Science 1969; 164: 719-721

8. Ribeiro EB, do Nascimento CM, Andrade IS, Hirata AE, Dolnikoff MS. Hormonal and metabolic adaptations to fasting in monosodium glutamate-obese rats. J Comp Physiol [B] 1997; 167: 430-437.

9. Bernardis LL, Patterson BD. Correlation between 'Lee index' and carcass fat content in weanling and adult female rats with hypothalamic lesions. J Endocrinol 1968; 40: 527528. eters, obese dams ( $\left.F_{1} M S G\right)$ were responsible for the appearance of obesity in the subsequent generation. Thus, obesity induced by neonatal MSG administration was not a worsening factor for reproduction. However, we conclude that this is a viable model for obtaining obesity in adult Wistar rats of the second generation. This might contribute to a better understanding of the pathophysiological mechanisms involved in transgenerational obesity.

\section{Acknowledgments}

The authors are grateful to the Research Support Center (RSC) for its valuable contribution to the study design and statistical analysis.
10. Clegg ED, Perreault SD, Klinefelter GR. Assessment of male reproductive toxicity. In: Hayes AW (Editor), Principles and methods of toxicology. Philadelphia: Taylor \& Francis; 2001. p 1263-1299.

11. Gelardi NL, Cha CJ, Oh W. Glucose metabolism in adipocytes of obese offspring of mild hyperglycemic rats. Pediatr Res 1990; 28: 641-645.

12. Soares JF, Siqueira AL. Comparando dois grupos. In: Soares JF (Editor), Introdução à estatística médica. Belo Horizonte: Segrac; 2001. p 174-223.

13. Vieira S. Outros delineamentos. In: Vieira $S$ (Editor), Estatística experimental. São Paulo: Atlas; 1997. p 119132.

14. Pasquali R, Pelusi C, Genghini S, Cacciari M, Gambineri A. Obesity and reproductive disorders in women. Hum Reprod Update 2003; 9: 359-372.

15. Lyra R, Neves G, Cavalcanti N. Obesity. In: Bandeira F (Editor), Endocrinologia e diabetes. Rio de Janeiro: Medisi; 2003. p 1023-1032.

16. Dolnikoff MS, Kater CE, Egami M, de Andrade I, Marmo MR. Neonatal treatment with monosodium glutamate increases plasma corticosterone in the rat. Neuroendocrinology 1988; 48: 645-649.

17. Gluckman PD, Hanson MA, Beedle AS. Non-genomic transgenerational inheritance of disease risk. Bioessays 2007; 29: 145-154.

18. Pivetta M. Da obesidade ao diabetes. Revista FAPESP http://www.revistapesquisa.fapesp.br/?art $=1996 \& b d=$ $1 \& \mathrm{pg}=1 \& \mathrm{lg}=$ =; 2003.

19. Rosmond R. Aetiology of obesity: a striving after wind? Obes Rev 2004; 5: 177-181. 